\title{
Health Screening among HBV Carriers in the Korean National Health and Nutrition Examination Survey V (KNHANES V)
}

\author{
Hyung Eun Son ${ }^{1}$, Sun Jae Jung², Aesun Shin ${ }^{3 *}$
}

\begin{abstract}
We aimed to investigate the differences in health screening, including medical checkups and cancer screening, between HBV carriers and non-carriers in the Republic of Korea. In the fifth Korean National Health and Nutrition Examination Survey (KNHANES V), conducted between 2010 and 2012, 17,865 persons who answered regarding their $\mathrm{HBV}$-infection status, medical checkup history, liver cancer screening and general cancer screening within the past years were included in the final analysis. In total, 295 persons were HBV carriers. Logistic regression models were used to compare the health check-up rate between the HBV carriers and nonHBV carriers. The HBV carriers were more likely to have been screened for liver cancer [adjusted odds ratio $(\mathrm{OR}): \mathbf{2 . 8 3}, 95 \%$ confidence interval $(95 \% \mathrm{CI}): \mathbf{1 . 9 0 - 4 . 2 1}$ ] or cancer [OR: 1.44, 95\% CI: 1.04-1.99]. The HBV carriers showed a probability of receiving medical checkups that was identical to that of the non-carriers [OR: 0.99, 95\% CI: 0.72-1.35]. The HBV carriers, who were at higher risk of developing chronic liver disease, were more likely to be screened for cancer, including liver cancer, than the non-HBV carriers; no difference in the rate of medical checkups was observed between the HBV carriers and non-HBV carriers.
\end{abstract}

Keywords: HBV - medical checkup - chronic liver diseases - liver cancer - liver cancer screening

Asian Pac J Cancer Prev, 16 (9), 3653-3657

\section{Introduction}

Hepatitis B virus (HBV) is a major cause of chronic liver diseases, including hepatocellular carcinoma (HCC). The prevalence of HCC in chronic hepatitis-B patients has been reported to be $2.7 \%, 11 \%, 25 \%$ and $35 \%$ at 5, 10, 15 and 20 years, respectively, after HBV infection, (Lee, 2005), and HBV is involved in approximately $70 \%$ of the HCC and $12 \%$ of occurrence of cholangiocarcinoma in the Korean population (Shin et al., 2011). With the introduction of a vaccination program in 1983, the prevalence of HBV carriers decreased from $8 \%$ in the 1980s to $3.7 \%$ in 2007 (Park et al., 2010; Yeo et al., 2013). Because of the health risk of HBV carriers, appropriate medical follow-ups should be conducted to prevent consequent HBV-related conditions (Sarkar et al., 2012; Song et al., 2013). According to the fourth Korean National Health and Nutrition Examination Survey (KNHANES IV), of 436 HBV-infected subjects, $27 \%$ were under regular liver cancer surveillance, and more than half of the HBV carriers had never received liver cancer screening (Park et al., 2012). Approximately $30 \%$ of the HBV carriers who participated in the cancerscreening program of the National Cancer Center in Korea were not aware of their infection status (Shin et al., 2009).

Individual, social, and economic factors determine health-related behaviors (Bae, 1993). This study used the KNHANES V (2010-2012) nationally representative survey to clarify the relationship between an awareness of HBV status and the use of medical care such as necessary medical services, medical screenings and cancer screenings.

\section{Materials and Methods}

\section{Data source}

The KNHANES survey is a nationally representative epidemiological study conducted in Korea. It is a study with multi-stage clustered-probability design, with a survey conducted in 20 households per primary sampling unit (PSU). In 2011, 192 PSUs were sampled from the 200,000 PSUs that are geographically defined throughout the country. The KNANES V survey includes annual surveys from 2010 to 2012 that consist of health interviews, physical examinations and nutrition surveys. The health interviews were conducted face-to-face by trained interviewers or self-administered in the mobile examination center (MEC). The physical examination and blood collection for the laboratory tests were conducted in the MEC (Kweon et al., 2014).

\section{Definition of $H B V$ carriers}

Among the 25,534 persons who participated in the KNHANES V survey, 17,886 persons over 18 years of

${ }^{1}$ Undergraduate, ${ }^{2}$ Department of Biomedical Sciences, ${ }^{3}$ Department of Preventive Medicine, Seoul National University College of Medicine, Seoul, Korea*For correspondence: shinaesun@snu.ac.kr 
age answered the question, "Have you ever been told by doctors or health professionals that you have been infected with HBV?" Because the aim of the study was to assess the awareness of HBV infection and health check-ups, the individuals who answered "yes" to this question were assigned to the HBV carriers group, regardless of their laboratory test results for HBsAg. Similarly, the participants who were seropositive for HBsAg as well as those who were unaware of their infection status were included in the non-HBV carrier group.

\section{Other measurements}

The age of the respondents was categorized into 10year groups. The monthly household income was divided into quarters adjusted by age and gender. The AUDIT score was used to rate the level of alcohol consumption (Conigrave et al., 1995), and self-rated stress, a depressive mood, and health status were included in the analysis. The participants were asked for the family history of chronic diseases including hypertension, diabetes, ischemic stroke, ischemic heart disease, and dyslipidemia. The participants were questioned regarding their health examination history, which included medical checkups, cancer screening and liver-cancer screening, in the previous two years. Finally, 17,865 recipients were analyzed after excluding 21 persons who did not answer any of the questions regarding health checkups.

\section{Statistical analysis}

A chi-square test was performed to compare the HBV carriers and non-carriers. Logistic regression models were used to calculate the odds ratios (ORs) for health-service utilization by awareness of the HBV infection status after adjustment for related socio-demographic factors. The crude ORs were compared with the ORs adjusted for certain variables, and the factors that caused significant changes in the ORs (more than 0.2) were included as covariates in the model. Every process was conducted with weighted values. The analyses were performed using the software SAS, version 9.4, (SAS Institute Inc., Cary, NC, USA).

\section{Ethics}

In the KNHANES survey, written informed consent was provided by every participant. The survey was conducted under the approval of the Institutional Review Board of Korea Centers for Disease Control and Prevention (IRB No. 2007-02CON-04-P for 2007, 2008-04EXP-01-C for 2008, 2009-02CON-03-2C for 2009, 2010-02CON-21-C for 2010, 2011-02CON-06-C for 2011, 2012-01EXP-01-2C for 2012). The statistical analysis using this publicly open dataset was approved by the Institutional Review Board of the Seoul National University Hospital in Seoul, Korea (IRB No. 1408-005598).

\section{Results}

\section{Baseline characteristics of the participants}

After excluding 21 persons who did not answer the questions regarding health checkups, 17,865 participants were included in the final analysis. Among them, 613 were HBsAg-positive by blood tests; 124 (18.4\%) of the participants were aware of their infection, and 171 answered that they were infected with HBV. A total of 295 participants were regarded as HBV-carriers with awareness of their infection status. Among the 295 reported carriers, 167 were men $(64.0 \%)$, and among the non-HBV carriers, 7,393 were men $(49.0 \%)$. The mean age of the non-HBV carriers was younger than that of the HBV carriers (Table 1). A total of $82.5 \%$ of the HBV carriers were living with their spouses, as were $67.6 \%$ of the non-HBV carriers. There were higher rates of current

Table 1. General Characteristics of the Self-reported HBV Carriers and Non-HBV Carriers, the Korean National Health and Nutrition Survey V (2010-2012)

\begin{tabular}{|c|c|c|c|}
\hline Variable & $\begin{array}{c}\text { HBV } \\
\text { carrier } \mathrm{N} \\
\text { (weighted \%) }\end{array}$ & $\begin{array}{c}\text { non-HBV } \\
\text { carrier } \mathrm{N} \\
\text { (weighted \%) }\end{array}$ & $\begin{array}{l}\text { Weighted } \\
\text { p-value } \\
\text { ) }\end{array}$ \\
\hline Overall & $295(1.6)$ & $17570(98.4)$ & \\
\hline Male & $167(64.0)$ & $7393(49.0)$ & $<0.0001$ \\
\hline Age & & & $<0.0001$ \\
\hline $20-29$ & $10(6.1)$ & $2070(19.6)$ & \\
\hline $30-39$ & $54(20.0)$ & $3251(20.8)$ & \\
\hline $40-49$ & $61(29.6)$ & $3106(21.5)$ & \\
\hline $50-59$ & $77(25.1)$ & $3344(18.1)$ & \\
\hline $60+$ & $93(19.2)$ & $5799(20.0)$ & \\
\hline Monthly household income & & & 0.077 \\
\hline 1st quartile & $58(22.3)$ & $4234(26.9)$ & \\
\hline 2nd quartile & $69(22.3)$ & $4390(25.6)$ & \\
\hline 3rd quartile & $78(25.4)$ & $4399(24.7)$ & \\
\hline 4th quartile & $88(30.0)$ & $4355(22.8)$ & \\
\hline Marital status & & & 0.0001 \\
\hline married, living together & $253(82.5)$ & $12914(67.6)$ & \\
\hline married, living apart & $26(9.6)$ & $2201(10.0)$ & \\
\hline Unmarried & $16(7.9)$ & $2445(22.5)$ & \\
\hline Education level & & & 0.0949 \\
\hline elementary school or less & ss $53(13.2)$ & $4548(18.9)$ & \\
\hline middle school & $49(12.2)$ & $1898(10.1)$ & \\
\hline high school & $96(38.8)$ & $5836(38.9)$ & \\
\hline college or more & $97(35.8)$ & $5268(32.1)$ & \\
\hline Cigarette smoking & & & 0.0014 \\
\hline never smoker & $145(41.1)$ & $10392(53.9)$ & \\
\hline ex-smoker & $70(23.9)$ & $3554(19.7)$ & \\
\hline current smoker & $80(35.1)$ & $3575(26.3)$ & \\
\hline Alcohol consumption & & & 0.2536 \\
\hline lower risk & $176(66.5)$ & $10239(62.3)$ & \\
\hline moderate risk & $47(19.2)$ & $3027(23.8)$ & \\
\hline higher risk & $20(8.3)$ & $867(6.8)$ & \\
\hline possible in dependence & $17(6.0)$ & $836(7.0)$ & \\
\hline \multicolumn{2}{|c|}{ Family history of chronic diseases } & & 0.089 \\
\hline Yes & $50(42.1)$ & $3064(52.2)$ & \\
\hline No & $58(57.9)$ & $2832(47.8)$ & \\
\hline \multicolumn{2}{|c|}{ Self-rated stress during normal activity } & & 0.5451 \\
\hline very severe & $10(2.9)$ & $758(4.5)$ & \\
\hline Severe & $65(20.7)$ & $3880(23.3)$ & \\
\hline Moderate & $170(62.0)$ & $10086(58.9)$ & \\
\hline Mild & $50(14.4)$ & $2795(13.3)$ & \\
\hline Depressive symptom & $37(14.0)$ & $2348(13.0)$ & 0.7098 \\
\hline Self-rated health status & & & 0.0381 \\
\hline Very good & $9(4.9)$ & $801(4.7)$ & \\
\hline Good & $69(20.5)$ & $5036(29.9)$ & \\
\hline Fair & $140(51.5)$ & $8304(48.0)$ & \\
\hline Bad & $58(18.8)$ & $2812(14.8)$ & \\
\hline Very bad & $19(4.2)$ & $616(2.6)$ & \\
\hline
\end{tabular}


smokers and ex-smokers among the HBV carriers relative to the non-HBV carriers. The HBV carriers were more likely to respond that their health status was "very bad".

Awareness of $H B V$ status and the rate of health screening

Table 2 shows the association between awareness of the HBV carrier status and health checkup history. The self-reported HBV carriers were more likely to receive cancer screening, particularly for liver cancer (OR 2.81, 95\%CI: 2.05-3.85) within the past two years. There was no difference in the rate for the general medical check-ups between the HBV carriers and non-carriers.

Table 2. Relationship between Awareness of HBV Status and the Rate of Health Screening within the Past Two Years, the Korea National Health and Nutrition Survey V (2010-2012)

\begin{tabular}{|c|c|c|c|}
\hline $\begin{array}{l}\text { Health } \\
\text { behavior }\end{array}$ & $\begin{array}{c}\text { HBV } \\
\text { carrier, } \mathrm{N} \\
\text { (weighted \%) }\end{array}$ & $\begin{array}{c}\text { Non-HBV } \\
\text { carrier, N } \\
\text { (weighted \%) }\end{array}$ & $\begin{array}{c}\text { Adjusted } \\
\text { OR* } \\
(95 \% \mathrm{CI})\end{array}$ \\
\hline \multicolumn{4}{|c|}{ Medical checkup } \\
\hline No & $113(39.8)$ & $7180(45.5)$ & \multirow[t]{2}{*}{$0.99(0.72-1.35)$} \\
\hline Yes & $182(60.2)$ & $10390(54.5)$ & \\
\hline \multicolumn{4}{|c|}{ Liver-cancer screening } \\
\hline No & $247(84.3))$ & $16556(95.0)$ & \multirow[t]{2}{*}{$2.83(1.90-4.21)$} \\
\hline Yes & $48(15.7))$ & $1014(5.0)$ & \\
\hline \multicolumn{4}{|c|}{ Cancer screening } \\
\hline No & $111(40.4)$ & $8058(53.2)$ & \multirow[t]{2}{*}{$1.44(1.04-1.99)$} \\
\hline Yes & $184(59.6)$ & $9512(46.8)$ & \\
\hline
\end{tabular}

* adjusted mutually for age, gender, marital status, smoking status and self-rated health status

Table 3. Characteristics of Participants and Likelihood of Taking General or Liver Cancer Screening, the Korean National Health and Nutrition Survey V (2010-2012)

\begin{tabular}{|c|c|c|c|c|}
\hline \multirow[t]{2}{*}{ Characteristics } & \multicolumn{2}{|c|}{ General cancer screening } & \multicolumn{2}{|c|}{ Liver cancer screening } \\
\hline & $\begin{array}{l}\text { No. of screened/ } \\
\text { unscreened }\end{array}$ & $\begin{array}{l}\text { Adjusted OR }{ }^{1} \\
(95 \% \mathrm{CI})\end{array}$ & $\begin{array}{l}\text { No. of screened/ } \\
\text { unscreened }\end{array}$ & $\begin{array}{l}\text { Adjusted OR }{ }^{1} \\
(95 \% \mathrm{CI})\end{array}$ \\
\hline \multicolumn{5}{|l|}{ HBV infection } \\
\hline non-HBV carrier & $10,391 / 7,180$ & 1.00 (ref) & $1,014 / 16,557$ & 1.00 (ref) \\
\hline HBV carrier & $182 / 113$ & $1.44(1.04-1.99)$ & $48 / 247$ & $2.83(1.90-4.21)$ \\
\hline \multicolumn{5}{|l|}{ Gender } \\
\hline Male & $4,854 / 2,707$ & 1.00 (ref) & $584 / 6977$ & 1.00 (ref) \\
\hline Female & $5,719 / 4,586$ & $2.23(2.00-2.50)$ & $478 / 9827$ & $0.60(0.48-0.76)$ \\
\hline \multicolumn{5}{|l|}{ Age (years) } \\
\hline $20-29$ & $650 / 1,430$ & 1.00 (ref) & $14 / 2,066$ & 1.00 (ref) \\
\hline $30-39$ & $1,502 / 1,803$ & $2.25(1.87-2.71)$ & $111 / 3,194$ & $3.49(1.49-8.16)$ \\
\hline $40-49$ & $2,134 / 1,033$ & $4.96(4.07-6.03)$ & $228 / 2,939$ & $6.34(2.63-15.29)$ \\
\hline $50-59$ & $2,429 / 993$ & $6.58(5.37-8.07)$ & $296 / 3,126$ & $8.41(3.50-20.24)$ \\
\hline $60-69$ & $3,858 / 2,034$ & $4.94(4.03-6.07)$ & $413 / 5,479$ & $7.00(2.91-16.81)$ \\
\hline \multicolumn{5}{|l|}{ Marital status } \\
\hline Married, living together & $8,464 / 4,704$ & 1.00 (ref) & $925 / 12,243$ & 1.00 (ref) \\
\hline Married, living apart & $1,244 / 983$ & $0.54(0.48-0.62)$ & $116 / 2,111$ & $0.91(0.69-1.20)$ \\
\hline Unmarried & $860 / 1,601$ & $0.32(0.27-0.38)$ & $20 / 2,441$ & $0.38(0.21-0.70)$ \\
\hline \multicolumn{5}{|l|}{ Smoking } \\
\hline Never smoker & $6,139 / 4,398$ & 1.00 (ref) & $537 / 10,000$ & 1.00 (ref) \\
\hline Ex-smoker & $2,396 / 1,228$ & $1.38(1.21-1.58)$ & $323 / 3,301$ & $1.20(0.93-1.55)$ \\
\hline Current smoker & $2,008 / 1,648$ & $0.79(0.70-0.90)$ & $198 / 3,458$ & $0.77(0.58-1.01)$ \\
\hline \multicolumn{5}{|l|}{ Self-rated health status } \\
\hline Very good & $454 / 356$ & 1.00 (ref) & $57 / 753$ & 1.00 (ref) \\
\hline Good & $3,029 / 2,076$ & $1.05(0.86-1.28)$ & $307 / 4,798$ & $0.93(0.65-1.34)$ \\
\hline Usual & $5,060 / 3,384$ & $1.07(0.87-1.32)$ & $507 / 7,937$ & $0.89(0.62-1.28)$ \\
\hline Bad & $1,680 / 1,191$ & $0.62(0.46-0.82)$ & $160 / 2,711$ & $0.84(0.57-1.22)$ \\
\hline Very bad & $349 / 286$ & $0.56(0.41-0.76)$ & $31 / 604$ & $0.59(0.34-1.05)$ \\
\hline
\end{tabular}

Adjusted for age, gender, marital status, smoking status and self-rated health status, mutually.
Attendance at general and liver cancer screenings and associated factors

Table 3 shows the association between demographic and lifestyle factors and attendance at general and liver cancer screenings. Among the study participants, those who were known to be HBV carriers tended to undergo general cancer screening and liver cancer screening more frequently [OR 1.44, 95\%CI: 1.04-1.99, and OR 2.83, 95\% CI: 1.90-.4.21, respectively]. Women were 2.23-fold [95\%CI: 2.00-2.50] more likely to participate in general cancer-screening programs; however, they showed a lower likelihood than men of attending liver cancer screening programs [OR 0.60, 95\%CI: 0.48-0.76]. The likelihood of general screening and liver cancer screening increased until age 50, then dropped after age 60 .

Compared to married people who live with a spouse, those participants who lived apart from a partner or unmarried participants were more likely not to attend general cancer screening [OR 0.54, 95\%CI: 0.48-0.62 in married participants who live apart from their spouse, OR 0.32 , 95\% CI: $0.27-0.38$ in unmarried participants] or liver cancer screening programs [OR $0.38,95 \% \mathrm{CI}$ : 0.21-0.70 in unmarried participants]. Ex-smokers tended to undergo more general cancer screening [OR 1.38, 95\%CI: 1.21-1.58], whereas current smokers were more likely not to participate in a screening program [OR 0.79 , 95\%CI: 0.70-0.90]. When respondents reported having very bad self-rated health status, they were not likely to be involved in general cancer screening programs [OR 0.56. 95\% CI: 0.41-0.76]. 


\section{Discussion}

In this study, the awareness of HBV infection status was significantly related to the cancer-screening rate, including screening for liver cancer, with no association with medical checkups. In South Korea, the National Cancer Screening Program (NCSP) covers stomach, liver, colorectal, breast and cervical cancer, which makes the rate of general cancer screening higher than before. As a result of a 10-year plan for cancer control, the 5-year survival rate for liver cancer in Korea has improved from $13.2 \%$ in $1996-2000$ to $23.3 \%$ in 2003-2008 (Yeo et al., 2013). NCSP liver cancer screening in high risk groups including HBV carriers is done with alpha-feto protein level and ultrasonography, making the higher rate of liver cancer screening in self-reported HBV carriers.

Several studies have examined the epidemiological characteristics of HBV carriers and health screening related factors (Ayers et al., 2010; Kim et al., 2010; Tanaka et al., 2011; Yang et al., 2013), though few studies have examined the relationship between an awareness of HBV status and health screening. Because HBV carriers are at a higher risk for other chronic liver diseases including hepatocellular carcinoma (HCC) and liver cirrhosis (Lee, 2005; Lee et al., 2012), close medical follow-up of HBV carriers is very important. Liver cancer occurs in populations with a well-defined set of risk factors and has a protracted preclinical phase, meaning that timely identification of disease can lead to appropriate treatment at a more curable stage (Noh et al., 2012). Despite the importance of health screening in the early diagnosis of $\mathrm{HBV}$ and regular follow-up of high-risk patients, only $18 \%$ of the blood test-confirmed HBV carriers were aware of their status, and this low awareness level was consistent with a previous report from the fourth KNHANES survey (2007-2009).

According to the previous studies, the likelihood of receiving medical checkups is affected by socioeconomic factors such as income, gender, health insurance, occupation and accompanying disability (Cho and Lee, 2011). Regarding cancer screening, similar, although different, factors are involved, such as gender, household income, previous cancer screening, health status, smoking status, physical activity and nutritional status (Kim et al., 2010). As a lot of factors affecting medical checkups and cancer screening, the factors considered in this study were adjusted with statistical ways. In this study, $60.2 \%$ of the HBV carriers had received medical checkups in the past two years, whereas $54.5 \%$ of the non-HBV carriers had.As carriers go to the clinic to check their HBV status through regular blood tests, they might not feel the need to seek medical check-ups other than liver screenings. Another potential explanation is that there is a misunderstanding of HBV hepatitis in the general population as well as a stigma against HBV carriers. In one survey in Japan, $17.1 \%$ of the participants answered that they worried regarding disease transmission, avoided contact with infected colleagues and had prejudiced opinions regarding infected colleagues (Eguchi and Wada, 2013). Misunderstandings and prejudices might lead HBV carriers to avoid necessary health screening (van der Veen et al., 2013).
Gender is significantly related to other socioeconomic factors that are significantly related to rates of liver-cancer screening [13]. Another study showed that the rate of cancer screening differed according to the health-related responsibility, stress management and health-promoting behaviors (Lee, 2010). Individuals older than 60 might be more likely to be unemployed and could not receive cancer screening in the workplace, resulting in a slight decrease in the magnitude of increasing rate in cancer screening, including liver-cancer screening. In our study, persons who lived with a spouse were more likely to have had medical checkups and cancer screening than those who did not live with partners in marriage or were unmarried. This result agrees with the result of a study showing that married men receive more medical checkups (Yim et al., 2012). In this study, being married or living with a partner affected the higher rates of medical checkups and cancer screening in males and females. One study showed that the rate of medical checkups are affected by many factors, and there are some factors such as medical insurance, employment and physical barriers, not being considered in this study (Culica et al., 2002).

The limitation of the study is the low agreement rate between the self-reported and blood test results for HBV infection. The HBV carrier status was assessed by a questionnaire, regardless of the results of the laboratory test; however, 489 persons who answered that they were not infected with HBV showed positive in a surface HBV antigen in blood test. This low agreement was previously reported from the report using the KNHANES IV data (Park et al., 2013). A previous study reported that awareness of HBV or HCV infection was the determinant for liver cancer screening, and hepatitis carriers confirmed by blood test and unaware of their infection did not differ with non-carriers in the screening rate (Cho et al., 2010). In addition, as it is a cross-sectional study, this study doesn't show causality between awareness of HBV status and health screening.

In summary, HBV carriers who were aware of their carrier status were more likely to have been screened for cancer, including liver cancer; there was no difference in the rate of general medical checkups. Considering the consequences of chronic HBV infection, raising the awareness of carrier status should be emphasized.

\section{Acknowledgements}

This study was supported by a grant from Seoul National University Hospital (2014).

\section{References}

Ayers JW, Juon HS, Lee S, Park E (2010). Hepatitis B vaccination prevalence and its predictors among Asian, Pacific Islander, Native American, and multiracial adults in the national health and nutrition examination Survey. $J$ Immigr Minor Health, 12, 847-52.

Bae SS (1993). Health-related behaviors: theoretical models and research findings. J Prev Med Public Health, 26, 508-33.

Cho B, Lee CM (2011). Current situation of national health screening systems in Korea. J Korean Med Assoc, 54, 666.

Cho ER, Shin A, Choi KS, et al (2010). Factors associated 
with use of ultrasonography screening for hepatocellular carcinoma among hepatitis B or C carriers. Cancer Epidemiol, 34, 713-6.

Conigrave KM, Saunders JB, Reznik RB (1995). Predictive capacity of the AUDIT questionnaire for alcohol-related harm. Addiction, 90, 1479-85.

Culica D, Rohrer J, Ward M, et al (2002). Medical checkups: who does not get them? Am J Public Health, 92, 88-91.

Eguchi H, Wada K (2013). Knowledge of HBV and HCV and individuals' attitudes toward HBV- and HCV-infected colleagues: a national cross-sectional study among a working population in Japan. PLoS One, $\mathbf{8}, 76921$.

Kim RB, Park KS, Hong DY, et al (2010). Factors associated with cancer screening intention in eligible persons for national cancer screening program. J Prev Med Public Health, 43, 62-72.

Kweon S, Kim Y, Jang MJ, et al (2014). Data resource profile: the Korea National Health and Nutrition Examination Survey (KNHANES). Int J Epidemiol, 43, 69-77.

Lee KS (2005). Viral Hepatitis: Focus on Clinical Manifestations of Hepatitis A, B and C. J Korean Medical Assoc, 48, 428-39.

Lee MS (2010). Comparison of health promotion behavior in middle aged rural residents by cancer screening participation. J Korean Acad Community Health Nurs Vol, 21, 43-52.

Lee SS, Byoun YS, Jeong SH, et al (2012). Type and cause of liver disease in Korea: single-center experience, 2005-2010. Clin Mol Hepatol, 18, 309-15.

Noh DK, Choi KS, Jun JK, et al (2012). Factors associated with attending the National Cancer Screening Program for liver cancer in Korea. Asian Pac J Cancer Prev, 13, 731-6.

Park B, Choi KS, Suh M, et al (2013). Factors associated with compliance with recommendations for liver cancer screening in Korea: a nationwide survey in Korea. PLoS One, , 86315.

Park NH, Chung YH, Lee HS (2010). Impacts of vaccination on hepatitis B viral infections in Korea over a 25-year period. Intervirology, 53, 20-8.

Park SH, Heo NY, Park JH, et al (2012). Hepatocellular carcinoma screening in a hepatitis B virus-infected Korean population. Dig Dis Sci, 57, 3258-64.

Sarkar M, Stewart S, Yu A, et al (2012). Hepatocellular carcinoma screening practices and impact on survival among hepatitis B-infected Asian Americans. J Viral Hepat, 19, 594-600.

Shin A, Cho ER, Kim J, et al (2009). Factors associated with awareness of infection status among chronic hepatitis B and $\mathrm{C}$ carriers in Korea. Cancer Epidemiol Biomarkers Prev, 18, 1894-8.

Shin A, Park S, Shin HR, et al (2011). Population attributable fraction of infection-related cancers in Korea. Ann Oncol, 22, 1435-42.

Song P, Gao J, Inagaki Y, et al (2013). Biomarkers: evaluation of screening for and early diagnosis of hepatocellular carcinoma in Japan and china. Liver Cancer, 2, 31-9.

Tanaka M, Katayama F, Kato H, et al (2011). Hepatitis B and $\mathrm{C}$ virus infection and hepatocellular carcinoma in China: a review of epidemiology and control measures. J Epidemiol, 21, 401-16.

van der Veen YJ, van Empelen P, Looman CW, Richardus JH (2013). Social-cognitive and socio-cultural predictors of hepatitis B virus-screening in turkish migrants, the netherlands. J Immigr Minor Health.

Yang HK, Shin DW, Hwang SS, et al (2013). Regional factors associated with participation in the national health screening program: a multilevel analysis using national data. J Korean Med Sci, 28, 348-56.

Yeo Y, Gwack J, Kang S, et al (2013). Viral hepatitis and liver cancer in Korea: an epidemiological perspective. Asian Pac J Cancer Prev, 14, 6227-31.
Yim HJ, Park HA, Kang JH, et al (2012). Marital Status and Health Behavior in Middle-aged Korean Adults. Korean $J$ Fam Med, 33, 390-7. 